Pedro Marques-Vidal

Alain Pécoud

Daniel Hayoz

Fred Paccaud

Vincent Mooser

Gérard Waeber

Peter Vollenweider

\title{
Prevalence of normal weight obesity in Switzerland: effect of various definitions
}

Received: 28 January 2008

Accepted: 10 June 2008

Published online: 5 July 2008

The CoLaus study was supported by research grants from GlaxoSmithKline and from the Faculty of Biology and Medicine of Lausanne, Switzerland.

P. Marques-Vidal

Cardiomet

CHUV

Lausanne, Switzerland

P. Marques-Vidal $(\bowtie) \cdot$ F. Paccaud Institute of Social and Preventive Medicine (IUMSP)

Centre Hospitalier Universitaire Vaudois and University of Lausanne

Bugnon 17

1005 Lausanne, Switzerland

Tel.: +41-21/314-7265

Fax: $+41-21 / 314-7373$

E-Mail: pedro-manuel.marques-vidal

@chuv.ch

\section{A. Pécoud}

Medical Outpatient Clinic

University of Lausanne

Lausanne, Switzerland

D. Hayoz

Dept. of Medicine

Vascular Medicine, CHUV

Lausanne, Switzerland

V. Mooser

Medical Genetics

GlaxoSmithKline

Philadelphia (PA), USA

G. Waeber $\cdot$ P. Vollenweider

Dept. of Medicine

Internal Medicine, CHUV

Lausanne, Switzerland
Abstract Background Normal weight obesity (NWO) is defined as an excessive body fat associated with a normal body mass index $\left(\right.$ BMI $\left.<25 \mathrm{~kg} / \mathrm{m}^{2}\right)$, but its prevalence in the general population is unknown. Aim of the study To assess the prevalence of NWO in Switzerland according to different cut points used to define excess body fat. Methods Cross-sectional study including 3,213 women and 2,912 men aged 35-75 years. Body fat was assessed by bioelectrical impedance analysis and prevalence of NWO was assessed using four previously published definitions for excess body fat. Results Percent body fat increased with age: in men, the values (mean \pm SD) were $20.2 \pm 5.4,23.0 \pm 5.4$, $26.3 \pm 5.2$ and $28.2 \pm 4.6$ for age groups 35-44, 45-54, 55-64 and 65-75 years, respectively; the corresponding values for women were $29.9 \pm 7.8,33.1 \pm 7.4,36.7 \pm 7.5$ and $39.6 \pm 6.9$. In men, prevalence of NWO was $<1 \%$ irrespective of the definition used. Conversely, in women, a 1- to 20 -fold difference (from 1.4 to $27.8 \%$ ) in NWO prevalence was found. The prevalence of NWO increased with age when age-independent cut points were used in women, but not in men. Conclusions Prevalence of NWO is low in the general popu- lation and higher in women than in men. The prevalence is highly dependent on the criteria used to define excess body fat, namely in women. The use of gender- and age-specific cut points to define excess body fat is better than fixed or gender-specific only cut points.

Key words cross-sectional study - normal weight obesity prevalence - Switzerland 


\section{Introduction}

Obesity is defined by an excess body fat [1], but in the absence of a simple technique to measure body fat in the general population, increased body mass index (BMI) has been widely used as a surrogate marker for excess body fat [1]. Recently, a new entity named normal weight obesity (NWO) has been described; NWO is defined as a normal BMI associated with increased body fat [6] and has been associated with an unfavorable lipid [6] and inflammatory [5] profile. Still, the exact prevalence of NWO in the general population has been seldom studied. Another difficulty arises as there is no established validated cut point to define excess body fat. Body fat levels vary according to gender and age $[6,11]$, and several cut points have been proposed to define excess body fat. For instance, the initial description of NWO used a single cut point of $30 \%$ to define excess body fat $[5,6]$, whereas other authors have proposed gender-specific, age-independent [27], or gender- and age-specific [11, 16] cut points. Further, there is no information regarding the potential effect of those different cut points on NWO prevalence rates.

Thus, the aim of the present study was to assess the prevalence of NWO according to those different cut points in the city of Lausanne, Switzerland.

\section{Subjects and methods}

\section{Sampling}

The sampling procedure of the CoLaus (Cohorte Lausannoise) study has been described previously [8]. Briefly, the complete list of the Lausanne inhabitants aged $35-75$ years $(n=56,694)$ was provided by the population registry of the city. A simple, nonstratified random selection of the subjects was performed and a random sample of $35 \%$ of the overall population was drawn. An invitation letter with a quick description of the study and a formulary in a pre-stamped envelope was sent to all randomized subjects. Subjects interested in participating returned the formulary and were contacted telephonically within 14 days by one of the staff members who provided more information about the study and arranged for an appointment.

Since the CoLaus study aimed at including only Caucasians to avoid population stratification and to increase genetic homogeneity for association studies, the following inclusion criteria were applied: (a) written informed consent; (b) aged 35-75 years; (c) willingness to take part in the examination and to have blood sample drawn and (d) Caucasian origin.
Caucasian origin was defined as having both parents and grandparents Caucasian.

Of the initial 19,830 subjects sampled, 54 subjects were considered as noneligible before contact and $15,109(76 \%)$ responses were obtained. A total of 4,667 subjects who did not respond were considered as nonresponders. Among responders, 6,189 (41\%) subjects refused to participate in the study and 799 (5\%) were considered as noneligible. Subjects who refused were older $(52.6 \pm 11.7$ vs. $51.2 \pm 10.9$ years, $P<0.01)$ and included more women (61 vs. 52\%, $P<0.01)$ than subjects who accepted to participate. The sample of 8,121 subjects who agreed to participate represented $41 \%$ of the initially sampled population, $54 \%$ of all responders and $57 \%$ of all eligible responders. Among these subjects, the first 6,738 were invited to attend the clinic and completed the examination. About 6,189 participants met the inclusion criteria (including ethnicity) and were included in the CoLaus study. The other 549 participants $(8.1 \%)$ were not of Caucasian ethnicity and were excluded. As the number of subjects who agreed to participate $(8,121)$ was higher than the number of subjects initially planned for the CoLaus study $(6,000), 1,383$ could not be included into the study although they were willing to participate. One subject withdrew after consent due to personal reasons. Therefore, the final CoLaus sample $(n=6,188)$ represents $43 \%$ of the eligible responders, $41 \%$ of all the responders and $31 \%$ of the initially sampled population.

\section{Assessment process}

All participants were asked to attend the outpatient clinic at the Centre Hospitalier Universitaire Vaudois (CHUV) in the morning after an overnight fast. Data were collected by trained field interviewers in an single visit lasting about $60 \mathrm{~min}$. Informed consent was obtained from participants upon their arrival at the study clinic. The first questionnaire mailed with the appointment's letter and completed by the participant prior to the morning visit was then quickly reviewed and a second questionnaire was applied by interview prior to clinical measurements and blood collection.

Data on smoking included the previous and current smoking status. Data on alcohol consumption included the past and current drinking status as well as the number of alcoholic beverage units (wine, beer and spirits) consumed over the week preceding the interview. Data on physical activity assessed whether the participant practiced leisure time physical activity at least twice per week. Whenever necessary (difficulty 
in understanding the questionnaire, irrespective of the reason), staff members helped the participants.

\section{Clinical data}

All staff members were trained and certified before participating in the study. Certification included ability to conduct all interviews, to perform phlebotomy and blood sample processing, anthropometric and blood pressure measurements, and data entry. The data was monitored by an external quality control organism (PRN, North Hampshire, UK). This external organism checked the integrity of the data by comparing the paper and the electronic information but had no access to the identification of the participants. The Ethics Committee was aware of this external data checking and the letter of consent also included the information that the data would be checked by an external organism.

Body weight and height were measured with participants standing without shoes in light indoor clothes. Body weight was measured in kilograms to the nearest $100 \mathrm{~g}$ using a Seca ${ }^{\circledR}$ electronic scale (Hamburg, Germany), which was calibrated yearly. Height was measured to the nearest $5 \mathrm{~mm}$ using a Seca ${ }^{\circledR}$ height gauge (Hamburg, Germany). BMI was defined as weight/height ${ }^{2}$. Waist and hip circumferences were measured as recommended [18].

Body composition was assessed by electrical bioelectrical impedance analysis [13, 14] using the Bodystat $^{\circledR} 1500$ analyzer (Isle of Man, British Isles). This device has been validated against reference methods $[9,12]$ and its results have been shown to be more accurate than those obtained using a dual frequency bioelectrical impedance analysis device [21]. The correlation between the bioelectrical impedance analysis device and the coefficient of variation for repeated measurements of electrical impedance is $0.7 \%$ [12]; the reproducibility has been shown to be between 1\% [12] and 5\% [19]; the intraclass correlation coefficient has been estimated at 0.987 [22] and its correlation with reference methods such as isotope dilution is between 0.855 [19] and 0.96 [21]. Subjects had to fast for at least $5 \mathrm{~h}$, not engage into strenuous physical activity the previous $12 \mathrm{~h}$ and abstain from consuming caffeine or alcohol-containing beverages $24 \mathrm{~h}$ before the analysis. All metallic adornments were removed, and measurement was performed after a 10min rest in the supine position in an air-conditioned room with a constant temperature of $20^{\circ} \mathrm{C}$. Care was taken that the subject did not touch any metallic component of the bed and that the inner part of the thighs did not touch each other. The electrodes were positioned in the right side of the body according to the manufacturer's recommendations: injecting leads
Table 1 Cut points used to define excess $\%$ of body fat

\begin{tabular}{lllll}
\hline $\begin{array}{l}\text { Age group } \\
\text { (years) }\end{array}$ & $\begin{array}{l}\text { De Lorenzo } \\
(\%)\end{array}$ & $\begin{array}{l}\text { NHANES } \\
(\%)\end{array}$ & $\begin{array}{l}\text { Other }^{\mathrm{a}} \\
(\%)\end{array}$ & $\begin{array}{l}\text { Switzerland }^{\mathrm{b}} \\
(\%)\end{array}$ \\
\hline Men & & & & \\
$35-44$ & 30 & 29.1 & 26 & 28.1 \\
$45-54$ & 30 & 29.1 & 29 & 28.7 \\
$55-64$ & 30 & 29.1 & 31 & 30.6 \\
$65-74$ & 30 & 29.1 & & 32.6 \\
Women & & & & \\
$35-44$ & 30 & 37.2 & 39 & 35.9 \\
$45-54$ & 30 & 37.2 & 41 & 36.5 \\
$55-64$ & 30 & 37.2 & 43 & 40.5 \\
$65-74$ & 30 & 37.2 & & 44.4 \\
\hline
\end{tabular}

The table presents the different cut-points used to define excess body fat by gender and age group. According to De Lorenzo [5], NHANES [27], other [11] and Switzerland [16]

${ }^{\mathrm{a}}$ For white subjects and BMI $>30 \mathrm{~kg} / \mathrm{m}^{2}$; age groups are $20-39,40-59$ and 60-79 years

$\mathrm{b}_{95} 5^{\text {th }}$ Percentile

were connected to the electrodes behind the finger and toe, whereas measuring leads were connected to the electrodes on the wrist and ankle. Measurement was conducted with a test current of $400 \mu \mathrm{A}$ (root mean square) at a frequency of $50 \mathrm{kHz}$, with an impedance measuring range of 30-1,000 $\Omega$ (accuracy $3 \Omega$ ). Conversely, no information was available regarding the equation used (proprietary). Body fat was expressed as percentage of total body weight (\%BF) or as fat mass index, defined as body fat (in $\mathrm{kg}$ ) divided by height $(\mathrm{m})$ squared $\left(\mathrm{kg} / \mathrm{m}^{2}\right)$ [17].

Normal weight obesity was defined as a BMI $<25 \mathrm{~kg} / \mathrm{m}^{2}$ and a \% body fat superior to several established cut points: gender- and age-independent as reported initially ( $30 \%$ for both men and women) $[5,6]$; fixed sex-specific values $(29.1 \%$ in men and $37.2 \%$ in women) as proposed in NHANES [27]; ageand gender-specific values derived from an international study (for instance, $\% \mathrm{BF}>26 \%$ among white men aged $20-39$ or $\% \mathrm{BF}>43 \%$ for white women aged 60-79) [11], and age- and gender-specific 95th percentiles for the Swiss population $(\% \mathrm{BF}>28.1,28.7$, 30.6 and $32.6 \%$ for men aged $35-44,45-54,55-64$ and 65-74, respectively; the corresponding values for women being 35.9, 36.5, 40.5 and 44.4\%) [16] (Table 1). Alternatively, normal weight obesity was also defined as a BMI $<25 \mathrm{~kg} / \mathrm{m}^{2}$ and a fat mass index $\geq 8.3 \mathrm{~kg} / \mathrm{m}^{2} \quad$ (men) $\quad$ or $\geq 11.8 \mathrm{~kg} / \mathrm{m}^{2} \quad$ (women) [17].

\section{Statistical analysis}

Statistical analyzes were performed using Stata 9.2 (Stata Corp, College Station, USA). Results were expressed as mean \pm standard deviation (SD) or as number of subjects and (percentage). Comparisons 
Table 2 Sample characteristics, overall and by gender

\begin{tabular}{|c|c|c|c|c|}
\hline & $\begin{array}{l}\text { Overall } \\
(n=6,125)\end{array}$ & $\begin{array}{l}\text { Women } \\
(n=3,213)\end{array}$ & $\begin{array}{l}\text { Men } \\
(n=2,912)\end{array}$ & $P$ value \\
\hline Age (years) & $53.1 \pm 10.8$ & $53.5 \pm 10.7$ & $52.6 \pm 10.8$ & 0.005 \\
\hline $\begin{array}{l}\text { Born in Switzerland } \\
\text { (\%) }\end{array}$ & $3,961(64.7)$ & $2,107(65.6)$ & $1,854(63.7)$ & 0.12 \\
\hline \multicolumn{5}{|l|}{ Education (\%) } \\
\hline Basic & $1,273(20.8)$ & $777(23.9)$ & $510(17.4)$ & \\
\hline Apprenticeship & $2,267(37.0)$ & $1,159(36.1)$ & $1,108(38.1)$ & $<0.001$ \\
\hline High school/college & $1,450(23.7)$ & $792(24.7)$ & $658(22.6)$ & \\
\hline University & $1,130(18.5)$ & $489(15.2)$ & $641(22.0)$ & \\
\hline \multicolumn{5}{|l|}{ Smoking status (\%) } \\
\hline Current & $1,660(27.1)$ & $804(25.0)$ & $856(29.3)$ & \\
\hline Former & $2,015(32.9)$ & $895(27.9)$ & $1,130(38.5)$ & $<0.001$ \\
\hline Never & $2,450(40.0)$ & $1,514(47.1)$ & $936(32.1)$ & \\
\hline Physical activity (\%) & $3,400(55.5)$ & $1,842(57.3)$ & 1,558 & 0.005 \\
\hline Alcohol drinking (\%) & $4,466(72.9)$ & $2,017(62.8)$ & $2,449(84.1)$ & $<0.001$ \\
\hline Height $(\mathrm{cm})$ & $168.6 \pm 9.3$ & $162.7 \pm 6.7$ & $175.0 \pm 7.3$ & $<0.001$ \\
\hline Weight (kg) & $73.6 \pm 15.0$ & $66.4 \pm 12.7$ & $81.5 \pm 13.1$ & $<0.001$ \\
\hline $\operatorname{BMI}\left(\mathrm{kg} / \mathrm{m}^{2}\right)$ & $25.8 \pm 4.5$ & $25.1 \pm 4.8$ & $26.6 \pm 4.0$ & $<0.001$ \\
\hline$\%$ Body fat & $29.3 \pm 8.0$ & $34.3 \pm 8.2$ & $23.8 \pm 6.0$ & $<0.001$ \\
\hline $\begin{array}{l}\text { Fat mass index } \\
\qquad\left(\mathrm{kg} / \mathrm{m}^{2}\right)\end{array}$ & $7.8 \pm 3.4$ & $8.9 \pm 3.7$ & $6.5 \pm 2.5$ & $<0.001$ \\
\hline Waist $(\mathrm{cm})$ & $89.3 \pm 13.2$ & $83.4 \pm 12.2$ & $95.7 \pm 11.1$ & $<0.001$ \\
\hline Hip (cm) & $101.7 \pm 9.2$ & $100.6 \pm 10.1$ & $102.9 \pm 7.8$ & $<0.001$ \\
\hline
\end{tabular}

Results are expressed as number of subjects and (percentage) or as mean \pm standard deviation. Between gender comparisons by $\chi^{2}$ or Student's $t$ test $B M I$ body mass index

were performed using Student's $t$ test and analysis of variance for quantitative variables, and using $\chi^{2}$ for qualitative variables. Statistical significance was assessed for $P<0.05$.

\section{Results}

\section{Sample characteristics}

Of the 6,188 subjects from the initial sample, 6,125 had data on body fat that allowed their classification. The other 63 were excluded from the analysis as no data on body fat was available. Their main clinical characteristics according to gender are summarized in Table 2.

Swiss nationals represented circa two thirds of the sample, and no differences were found between genders. Six out of 10 subjects reported a current or previous history of smoking, and slightly more than half reported engaging in leisure physical activity at least twice per week. Also, almost three quarters of the subjects reported some type of alcohol consumption.

Between-gender comparisons showed that women were older, had a lower educational level, smoked and drank less and were more physically active than men. Women also had lower BMI, waist and hip but a higher \% body fat and a higher fat mass index than men. Finally, in both genders, body fat levels (ex-
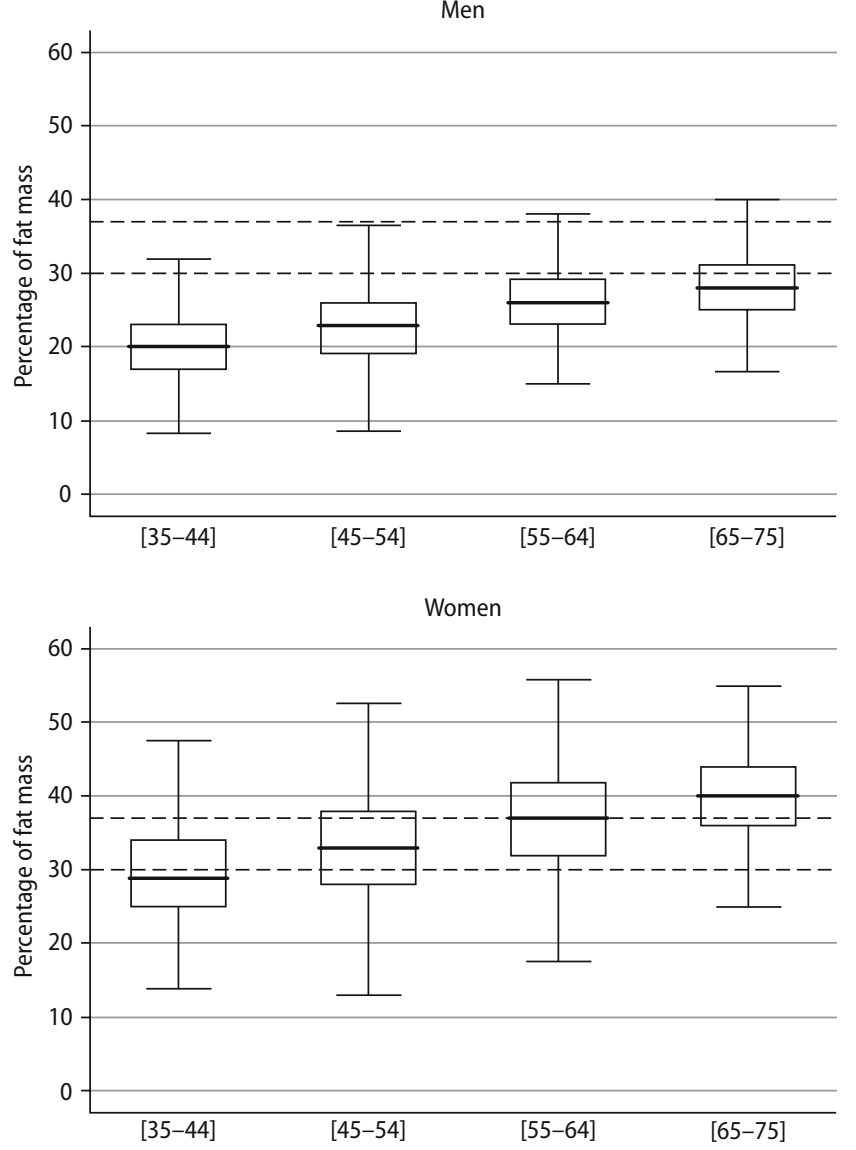

Fig. 1 Distribution of body fat (expressed as percentage of total body weight) according to gender and age group. The 30 and $37 \%$ thresholds to define obesity are indicated by the dashed lines

pressed in $\%$ of body weight) increased with age (Fig. 1).

\section{Prevalence of normal weight obesity}

The prevalence rates of NWO according to gender, age group and the cut point used to define excess $\mathrm{BF}$ are summarized in Table 3. In men, prevalence of NWO was below $1 \%$ irrespective of the definition used, whereas in women a 1 - to 20 -fold difference in the prevalence of NWO was found when \% body fat thresholds were used. Conversely, the fat mass indexbased definition led to a very low prevalence of NWO for both genders (Table 3). In women, the prevalence of NWO also increased with age when age-independent cut points were used, whereas no such increase with age was found in men. Finally, irrespective of the definition used, prevalence of NWO was considerably higher in women than in men, with the exception of the definition based on fat mass index (Table 3). 
Table 3 Prevalence of normal weight obesity by gender and age group according to the cut-point used to define excess body fat

\begin{tabular}{lrrrrrr}
\hline Age group $n$ & De Lorenzo & NHANES & & Other $^{c}$ & Switzerland $^{d}$ & $\begin{array}{l}\text { Fat mass } \\
\text { index }\end{array}$ \\
\hline Men & & & & & & \\
All & 2,912 & $21(0.7)$ & $29(1.0)$ & $24(0.8)$ & $17(0.6)$ & $1(0.1)$ \\
$35-44$ & 873 & $2(0.2)$ & $3(0.3)$ & $3(0.3)$ & $3(0.3)$ & $0(0.0)$ \\
$45-54$ & 840 & $4(0.5)$ & $5(0.6)$ & $6(0.7)$ & $6(0.7)$ & $0(0.0)$ \\
$55-64$ & 760 & $4(0.5)$ & $5(0.7)$ & $6(0.8)$ & $3(0.4)$ & $0(0.0)$ \\
$65-75$ & 439 & $11(2.5)$ & $16(3.6)$ & $9(2.1)$ & $5(1.1)$ & $1(0.2)$ \\
Women & & & & & & \\
All & 3,213 & $892(27.8)$ & $222(6.9)$ & $44(1.4)$ & $80(2.5)$ & $2(0.1)$ \\
$35-44$ & 857 & $128(14.9)$ & $9(1.1)$ & $6(0.7)$ & $17(2.0)$ & $0(0.0)$ \\
$45-54$ & 906 & $229(25.3)$ & $29(3.2)$ & $6(0.7)$ & $35(3.9)$ & $1(0.1)$ \\
$55-64$ & 932 & $322(34.6)$ & $75(8.1)$ & $11(1.2)$ & $18(1.9)$ & $0(0.0)$ \\
$65-75$ & 518 & $213(41.1)$ & $109(21.0)$ & $21(4.1)$ & $10(1.9)$ & $1(0.2)$ \\
\hline
\end{tabular}

Results are expressed as number of subjects and (percentage). Definitions used: BMI $<25 \mathrm{~kg} / \mathrm{m}^{2}$

${ }^{a} G$ Gender- and age-independent (30\% for both men and women) $[5,6]$

${ }^{\mathrm{b}}$ Fixed sex-specific values (29.1\% in men and $37.2 \%$ in women) [27]

'Age- and gender-specific values (\%BF $>26 \%$ among white men aged 20 39 years or $\% \mathrm{BF}>43 \%$ for white women aged $60-79$ years) [11]

${ }^{d}$ Age- and gender-specific 95th percentiles for the Swiss population (\%BF $>28.1,28.7,30.6$ and $32.6 \%$ for men aged $35-44,45-54,55-64$ and $65-$ 74 years, respectively; the corresponding values for women being $35.9,36.5$, 40.5 and $44.4 \%)$ [16]

${ }^{\mathrm{e}}$ Fat mass index $\geq 8.3 \mathrm{~kg} / \mathrm{m}^{2}$ (men) or $\geq 11.8 \mathrm{~kg} / \mathrm{m}^{2}$ (women) [17]

\section{Discussion}

There is little if no information regarding the prevalence of NWO in the general population. In this study, we tried to assess the prevalence of this entity using several cut points for excess body fat as proposed in the literature. Since in this study body fat was assessed by bioelectrical impedance analysis, we chose to use age- and gender-specific bioimpedance-derived cut points which had been proposed for the Swiss population [16]; alternatively, other bioimpedancederived cut points from an international study [11] or the USA [27], and the $>30 \%$ cut-off obtained by DXA [5] were also used. Overall, our results indicate that in men the prevalence of NWO was below $1 \%$ for all thresholds used, but that in women the prevalence of NWO varied considerably from 1.4 to $27.8 \%$ according to the cut-off used. Interestingly, using age- and gender-specific cut points $[11,16]$ led to more similar results than using a single cut-off $[5,27]$. As it has been shown that body fat increases with age $[3,11$, 16 , the use of a single cut-off value might overestimate the prevalence of excess fat in the elderly groups and, inversely, underestimate this condition in the younger groups. The increase of body fat with age might also explain the higher prevalence of NWO when using a single cut-off [5, 27] (see Fig. 1). Finally, the use of increased fat mass index to define NWO led to a very low prevalence in both genders; a possible explanation is the fact that fat mass index is dependent both on the percentage of body fat but also on the value of BMI (as fat mass index can be derived as $\% \mathrm{BF} \times \mathrm{BMI}$ ), and for subjects with a BMI below $25 \mathrm{~kg} / \mathrm{m}^{2}$ values of $\% \mathrm{BF}$ as high as $33 \%$ (for men) and $47 \%$ (for women) would be needed to reach the published thresholds [17]; those values are considerably higher than the thresholds used by the other authors (see Table 1). Hence, it is possible that the thresholds of fat mass index to define NWO might be excessive, and further studies are needed to better assess this point.

This study has some limitations that should be taken into account. First, only Caucasians were included, and it might be necessary to use ethnic-specific cut-points as proposed by others [3, 7, 27]. Second, the assessment of body fat was performed using bioelectrical impedance analysis, which might underestimate the values relative to DXA $[20,25]$, although this statement has been challenged [2, 4], namely among normal weight subjects [23]. Thus, it is rather unlikely that the high prevalence of women with NWO observed in this study using cut points obtained by DXA $[5,6]$ was due to an underestimation of body fat by bioelectrical impedance analysis. Third, our study did not include subjects aged over 75 years, and it would have been interesting to assess the prevalence of NWO in this age group. Still, the results obtained among participants aged 65-75 years indicate that the prevalence of NWO varies considerably depending on the definition used, and that agespecific cut-points to define excess body fat might be necessary, although further studies are needed to better assess this point. Fourth, the participation rate was rather low (41\%), which might limit the generalization of our findings. However, low participation is typical of surveys in Western countries and is comparable with the MONICA surveys conducted in Switzerland and in other countries [26]. The magnitude of the nonparticipation bias is not proportional to the percentage of nonparticipants [10] and a study on representativeness observed that people with risky behaviors participated in the same proportions as people without risk factors [24]. Finally, it has been shown that the NHANES and Geneva bioelectrical impedance analysis equations estimate body composition equally well in men but showed some discrepancies in women [15]; thus, it is likely that the differences in the prevalence of NWO women as derived from the Swiss or the USA cut points might partly be due to differences in estimation methods.

In summary, our data indicate that prevalence of NWO is low in the Caucasian population of Lausanne and higher in women than in men. Our results also indicate that the prevalence of NWO in women is highly dependent on the cut point used to define ex- 
cess body fat, and efforts are needed to establish appropriate body fat cut points if the prevalences are to be compared between surveys.

Acknowledgments Pedro Marques-Vidal made the statistical analysis and wrote part of the article. Alain Pécoud, Daniel Hayoz, Fred Paccaud, Vincent Mooser, Gérard Waeber and Peter Vollenweider contributed to the statistical analysis design, wrote part of the article and made major corrections. We also thank Yolande
Barreau, Anne-Lise Bastian, Binasa Ramic, Martine Moranville, Martine Baumer, Marcy Sagette, Jeanne Ecoffey and Sylvie Mermoud for data collection. The CoLaus study was supported by research grants from GlaxoSmithKline and from the Faculty of Biology and Medicine of Lausanne, Switzerland.

Conflict of interest Vincent Mooser is a full-time employee of GlaxoSmithKline. The other authors report no possible conflict of interest.

\section{References}

1. World Health Organization (2000) Obesity: preventing and managing the global epidemic. Report of a WHO consultation. World Health Organization Technical Report Series, vol 894, p i-253

2. Andreoli A, Melchiorri G, De Lorenzo A, Caruso I, Sinibaldi SP, Guerrisi M (2002) Bioelectrical impedance measures in different position and vs dualenergy X-ray absorptiometry (DXA). J Sports Med Phys Fitness 42:186-189

3. Chumlea WC, Guo SS, Kuczmarski RJ, Flegal KM, Johnson CL, Heymsfield SB, Lukaski HC, Friedl K, Hubbard VS (2002) Body composition estimates from NHANES III bioelectrical impedance data. Int J Obes Relat Metab Disord 26:1596-1609

4. De Lorenzo A, Andreoli A, Fusco A, Magnani A, D'Orazio N, Bertoli A (2000) Effect of subclinical hypothyroidism on body fluid compartments. Horm Metab Res 32:359-363

5. De Lorenzo A, Del Gobbo V, Premrov MG, Bigioni M, Galvano F, Di Renzo L (2007) Normal-weight obese syndrome: early inflammation? Am J Clin Nutr 85:40-45

6. De Lorenzo A, Martinoli R, Vaia F, Di Renzo L (2006) Normal weight obese (NWO) women: an evaluation of a candidate new syndrome. Nutr Metab Cardiovasc Dis 16:513-523

7. Deurenberg-Yap M, Chew SK, Deurenberg P (2002) Elevated body fat percentage and cardiovascular risks at low body mass index levels among Singaporean Chinese, Malays and Indians. Obes Rev 3:209-215

8. Firmann M, Mayor V, Marques-Vidal $\mathrm{P}$, Bochud $\mathrm{M}$, Pécoud $\mathrm{A}$, Hayoz $\mathrm{D}$, Paccaud F, Preisig M, Song KS, Yuan X, Danoff TM, Stirnadel HA, Waterworth DM, Mooser V, Waeber G, Vollenweider P (2008) The CoLaus study: a population-based study to investigate the epidemiology and genetic determinants of cardiovascular risk factors and metabolic syndrome. BMC Cardiovasc Disord 8:6

9. Fuller NJ, Sawyer MB, Elia M (1994) Comparative evaluation of body composition methods and predictions, and calculation of density and hydration fraction of fat-free mass, in obese women. Int J Obes Relat Metab Disord 18:503-512

10. Galea S, Tracy M (2007) Participation rates in epidemiologic studies. Ann Epidemiol 17:643-653

11. Gallagher D, Heymsfield SB, Heo M, Jebb SA, Murgatroyd PR, Sakamoto Y (2000) Healthy percentage body fat ranges: an approach for developing guidelines based on body mass index. Am J Clin Nutr 72:694-701

12. Ghosh S, Meister D, Cowen S, Hannan WJ, Ferguson A (1997) Body composition at the bedside. Eur J Gastroenterol Hepatol 9:783-788

13. Kyle UG, Bosaeus I, De Lorenzo AD, Deurenberg $P$, Elia $M$, Gómez JM, Heitmann BL, Kent-Smith L, Melchior JC, Pirlich M, Scharfetter H, Schols AM, Pichard C (2004) Bioelectrical impedance analysis-part I: review of principles and methods. Clin Nutr 23:12261243

14. Kyle UG, Bosaeus I, De Lorenzo AD, Deurenberg $P$, Elia $M$, Gómez JM, Heitmann BL, Kent-Smith L, Melchior JC, Pirlich M, Scharfetter H, Schols WJ, Pichard C (2004) Bioelectrical impedance analysis-part II: utilization in clinical practice. Clin Nutr 23:14301453

15. Kyle UG, Genton L, Lukaski HC, Dupertuis YM, Slosman DO, Hans D, Pichard C (2005) Comparison of fat-free mass and body fat in Swiss and American adults. Nutrition 21:161-169
16. Kyle UG, Genton L, Slosman DO, Pichard C (2001) Fat-free and fat mass percentiles in 5225 healthy subjects aged 15 to 98 years. Nutrition 17:534541

17. Kyle UG, Schutz Y, Dupertuis YM, Pichard C (2003) Body composition interpretation. Contributions of the fatfree mass index and the body fat mass index. Nutrition 19:597-604

18. Lohman TG, Roche AF, Martorell $\mathrm{R}$ (1991) Anthropometric standardization reference manual: abridged edition. Human Kinetics Books, Champaign, $\mathrm{p}$ i-90

19. Martin A, O'Sullivan AJ, Brown MA (2001) Body composition and energy metabolism in normotensive and hypertensive pregnancy. BJOG 108: 1263-1271

20. Neovius M, Hemmingsson E, Freyschuss B, Udden J (2006) Bioelectrical impedance underestimates total and truncal fatness in abdominally obese women. Obesity (Silver Spring) 14:1731-1738

21. Simpson JA, Lobo DN, Anderson JA, Macdonald IA, Perkins AC, Neal KR, Allison SP, Rowlands BJ (2001) Body water compartment measurements: a comparison of bioelectrical impedance analysis with tritium and sodium bromide dilution techniques. Clin Nutr 20:339-343

22. Steiner MC, Barton RL, Singh SJ, Morgan MD (2002) Bedside methods versus dual energy X-ray absorptiometry for body composition measurement in COPD. Eur Respir J 19:626-631

23. Sun G, French CR, Martin GR, Younghusband B, Green RC, Xie YG, Mathews M, Barron JR, Fitzpatrick DG, Gulliver W, Zhang H (2005) Comparison of multifrequency bioelectrical impedance analysis with dual-energy X-ray absorptiometry for assessment of percentage body fat in a large, healthy population. Am J Clin Nutr 81:74-78 
24. Taylor AW, Dal GE, Gill T, Chittleborough CR, Wilson DH, Adams RJ, Grant JF, Phillips P, Ruffin RE (2006) Do people with risky behaviours participate in biomedical cohort studies? BMC Public Health 6:11

25. Vasudev S, Mohan A, Mohan D, Farooq S, Raj D, Mohan V (2004) Validation of body fat measurement by skinfolds and two bioelectric impedance methods with DEXA - the Chennai Urban Rural Epidemiology Study (CURES-3). J Assoc Physicians India 52:877-881
26. Wolf HK, Kuulasmaa K, Tolonen $\mathrm{H}$, Ruokokoski E (1998) Participation rates, quality of sampling frames and sampling fractions in the MONICA surveys, 15 September, 1998. Helsinki, Finland, WHO MONICA. Quality assessment reports
27. Zhu S, Wang Z, Shen W, Heymsfield SB, Heshka S (2003) Percentage body fat ranges associated with metabolic syndrome risk: results based on the third National Health and Nutrition Examination Survey (1988-1994). Am J Clin Nutr 78:228-235 